\title{
Mineiridade e adesão religiosa: uma análise da expansão pentecostal e da resistência católica em duas regiões mineiras
}

\author{
Paulo Gracino Souza JR.*
}

\begin{abstract}
Resumo: Este estudo analisa as variáveis que contribuem para uma assimetria no que diz respeito à adesão religiosa apresentada pelo território de Minas Gerais. Como podemos observar pelos números que emergem do último censo do IBGE (2000), grande parte do território do estado constitui-se como uma das searas mais inóspitas ao crescimento pentecostal, configurando-se, junto com alguns outros estados, como uma das trincheiras avançadas da resistência católica. No entanto, em contraste com microrregiões como as de Ouro Preto, onde os que se declaram pentecostais não atingem a casa dos 5\%, existem outras como a microrregião de Ipatinga, que apresenta a surpreendente cifra de $22,71 \%$, a maior do estado. Nesse sentido, pensamos ser possível relacionar os índices supracitados a suas possíveis relações com o contexto sociocultural do estado, mais especificamente com o conjunto de características atribuídas à identidade mineira, o que alguns sociólogos qualificaram como "mineiridade". Tentaremos avaliar de que forma variáveis como família, pouca mobilidade demográfica, bem como a notória tradição católica, criam um contexto cultural bastante regulamentado, compondo um quadro desfavorável para o crescimento pentecostal.
\end{abstract}

Palavras-chave: pentecostalismo; cultura local; mineiridade; identidade.

\section{Introdução}

Este estudo pretende analisar os baixos índices de adesão ao pentecostalismo protestante $^{1}$ no estado de Minas Gerais, em suas possíveis relações com o contexto sociocultural

\footnotetext{
* Doutorando em Sociologia pela UERJ.

1. Segundo variada gama de autores, podemos identificar historicamente como pentecostal o movimento sócio-religioso surgido no início do século passado (1906), na cidade de Los Angeles, Estados Unidos. Este movimento busca seus fundamentos no cristianismo primitivo e reafirma a atualidade dos "dons" do Espírito Santo, tendo como principal ponto identificador o "dom de falar em línguas" estranhas (glossolalia), ou estrangeiras (xenoglassia), eventos que têm suas raízes em Atos II e Corinto. Não obstante ta conceituação, existem inúmeras divergências classificatórias embasadas na intensa dinâmica do campo pentecostal, que tem alimentado calorosos debates entre os estudiosos. No presente trabalho, tomamos como pentecostais os movimentos cristãos que dão ênfase às experiências de recebimento dos dons do Espírito Santo (Mariz, 1998).
}

do estado, mais especificamente com o conjunto de características atribuídas à identidade mineira, o que alguns sociólogos qualificaram como "mineiridade". 2

Tentaremos avaliar de que forma variáveis como família, pouca mobilidade demográfica, bem como a notória tradição católica, criam um contexto cultural bastante regulamentado,

\footnotetext{
2. Tomamos o termo como um dispositivo discursivo que tenta unificar as características e o modo de ação do habitante do estado de Minas Gerais. A "mineiridade", ou seja, a "formulação de um conjunto específico de valores atribuídos a um grupo" (Bomeny, 1994, p. 56) pode ser definida como o termo que traduz a conjunção de diversos elementos que constituem o povo mineiro, tais como apego à tradição, valorização da ordem; prudência, aversão a posições extremistas e, portanto, o centrismo, a moderação, o espírito conciliador; a capacidade de acomodar-se às circunstâncias e, ao mesmo tempo, efetuar transações; a habilidade, a paciência como estratégias para o alcance de objetivos políticos com menor custo (Dulci, 1984).
} 
compondo um quadro desfavorável para o crescimento pentecostal. Ao tocar nesse ponto, acreditamos que muitas questões correlatas surgirão, em sua maioria ligadas ao processo de globalização cultural e a seu alcance. Pois, como observa Berger (2004, p. 19), "há muito tempo que a modernização corrói a autoridade da tradição e da coletividade".

Dessa forma, como falar em elementos como tradição, família e cultura local como impeditivos da expansão pentecostal no território mineiro? A resposta a essa questão não é fácil, exigindo considerarmos, nesse processo, elementos como "assimilação", "localização" e "hibridação", que fazem parte da relação entre global e local, tal como observam Peter Berger e Samuel Huntington (2004).

Nesse sentido, pensamos ser possível fazer uma relação entre o fortalecimento do poder identitário da "mineiridade" e sua incorporação a circuitos comerciais, no que se convencionou chamar de "turismo histórico". Uma vez que, para boa parcela da população mineira incluída nesses circuitos turísticos, torna-se estrategicamente desinteressante transitar para fora desse contexto identitário.

No que diz respeito ao pentecostalismo, não acreditamos que a sua adesão se faça por meio de rupturas drásticas com o passado préconversão, mas por passagens (Birman, 1997), reacomodações de identidades que já haviam sido mexidas por processos ulteriores. Aderir ao pentecostalismo seria, entre outras coisas, uma forma de reatar, de situar-se em meio ao vendaval identitário contemporâneo.

Faz-se necessário frisar que essa proposta interpretativa não é, de maneira nenhuma, uma reedição das teses funcionalistas das décadas de 1960/70. ${ }^{3}$ Não se trata, aqui, de uma adaptação aos novos contextos modernos - quem sabe pós-modernos - ou de uma contenção do caráter anômico de uma sociedade que se desintegra, mas de um processo de rearranjo das formas identitárias.

Vemos esse rearranjo não como uma transição da identidade "católica brasileira" para uma

3. Emílio Willems (1967), Christian Lalive d'Epinay (1970), Candido Procópio Ferreira de Camargo $(1968,1973)$ e Beatriz Muniz de Souza (1969, 1973). identidade protestante-pentecostal, como chegam a afirmar alguns pesquisadores norte-americanos (Stoll, 1990; Martin, 1990), mas como uma substituição dos antigos dispositivos discursivos identitários universais, para lembrar Stuart Hall (2000), por identidades locais pontuais e fragmentadas. Teríamos, então, não uma reacomodação definitiva, uma eliminação da anomia como o termo é entendido por Durkheim -, mas o contrário.

A hegemonia católica está ameaçada, isso parece certo. Mas em seu lugar não surge e, muito provavelmente não surgirá, nenhuma outra macronarrativa, conquanto pululem narrativas locais que devam atender aos interesses específicos desses grupos pontuais.

Várias denominações pentecostais, com destaque para a Assembléia de Deus, têm sido capazes de arrebanhar essa miríade de símbolos e interesses através de uma estrutura organizativa descentralizada, mas nada impede que a própria Igreja Católica ocupe esses espaços, como já vem fazendo com as comunidades leigas, seja por meio das Comunidades Eclesiais de Base ou da própria Renovação Carismática Católica.

Para compreender essas questões, analisaremos esses processos nas microrregiões mineiras de Ouro Preto e Ipatinga, ${ }^{4}$ escolhidas porque representam casos significativos e extremos para nossa argumentação. Isso porque a microrregião de Ouro Preto representa um caso paradigmático da inserção pentecostal em Minas, não atingindo a casa dos 5\% (4,85\%), ao passo que a de Ipatinga mostra-se como seu antípoda, apresentando a surpreendente cifra de $22,71 \%$.

\section{Da modernização ao mercado: eixos explicativos do crescimento pentecostal no Brasil}

Como observaremos pelo exposto a seguir, a maioria dos estudos sobre o pentecostalismo

4. A microrregião de Ipatinga conta com 474.147 habitantes, distribuídos nos seguintes municípios: Açucena, Antônio Dias, Belo Oriente, Coronel Fabriciano, Ipatinga, Jaguaruçu, Joanésia, Marliéria, Mesquita, Naque, Periquito, Santana do Paraíso, Timóteo. A microrregião de Ouro Preto conta com 154.860 habitantes, distribuídos nos municípios de Diogo Vasconcelos, Itabirito, Mariana e Ouro Preto. 
é motivada pelo seu significativo crescimento e pela conseqüiente exposição na arena pública. Se olharmos o mapa religioso brasileiro, traçado a partir do último censo do Instituto Brasileiro de Geografia e Estatística (IBGE, 2000), vemos um país bem diferente do que proclamou Nossa Senhora Aparecida como padroeira universal do Brasil (Della Cava, 1975), em 1930. Notamos que lentamente o panorama religioso brasileiro vem se diversificando, forçando significativas mudanças na sociedade civil, no Estado e, por que não, nas ciências sociais.

O país que contava com uma inquestionável maioria católica (segundo o censo de 1940 eram $95,2 \%$ ) assiste a essas cifras declinarem nas seis décadas posteriores, até chegarmos aos atuais $73,8 \%$ do censo de 2000 . Essa queda substancial no número de católicos é fruto de um expressivo aumento dos que se declaram sem religião, que já atingem $7,3 \%$, mas, principalmente, do aumento exacerbado dos evangélicos pentecostais, que nas ultimas três décadas saltaram de 3,55\%, em 1970, para 10,58\% da população, no censo 2000 . O fenômeno do vertiginoso crescimento pentecostal não é privilégio do Brasil - segundo estimativas, eles já somam meio bilhão no mundo todo, ${ }^{5}$ tendo como principal foco de sua expansão a América Latina. Fato que levou alguns afoitos pesquisadores a acreditarem que estávamos passando por uma verdadeira "reforma protestante" (ver Stoll, 1990; Martin, 1990).

No entanto, um exame mais criterioso no mapa religioso brasileiro, traçado a partir dos dados do IBGE 2000, mostra-nos que, a despeito do significativo crescimento pentecostal nas últimas décadas, sua inserção no território nacional é desigual e bastante restrita em alguns estados. Embora os pentecostais atinjam cifras muito significativas em algumas partes do território nacional, principalmente nos estados da Região Norte, com destaque para Rondônia (estado mais pentecostal do país, com 17,97\%), ou em grandes cidades como Rio de Janeiro $(13,72 \%)$ e São Paulo $(13,13 \%),{ }^{6}$ mostram-se

5. Ver estimativas mundiais em www.infobrasil.org, cuja fonte original é a World evangelization.

6. É interessante observar que, embora São Paulo e Rio de Janeiro não ocupem o topo do ranking do IBGE como os estados mais pentecostais do país, ficando em $10^{\circ}$ e $9^{\circ}$ luga- pouco significativos em outros tantos, ficando bem abaixo da média nacional em estados como os do Nordeste. Em Sergipe e Piauí, estados menos pentecostais do Brasil, por exemplo, não chegam à casa dos $5 \%$, ficando com $4,36 \% \mathrm{e}$ $4,49 \%$, respectivamente.

É justamente nesse ponto que chamamos atenção para nosso objeto. Embora os dados para Minas Gerais, no que diz respeito ao pentecostalismo, não se afastem muito da média nacional, ficando na casa dos $9,23 \%$ (contra os $10,58 \%$ do país), sua distribuição territorial é bastante díspar. Uma análise detalhada desses números nos mostra que significativa parcela dos pentecostais mineiros, $51,27 \%$, concentrase em apenas 5 das 66 microrregiões geográficas em que se divide o estado, reservando para as demais áreas números próximos aos dos estados do Nordeste.

Posto nesses termos, pode-se dizer que Minas Gerais, em quase todo seu território, continua como um dos celeiros do catolicismo no Brasil. Sendo o estado uma das searas mais inóspitas ao proselitismo pentecostal e motivo de preocupação até mesmo para algumas organizações evangélicas, como é o caso do Serviço de Evangelização para a América Latina (Sepal), ${ }^{7}$ que aponta o território mineiro como um grande desafio. ${ }^{8}$

Avançando um pouco mais em nossas conjecturas, observamos que as áreas de maior resistência ao pentecostalismo em Minas

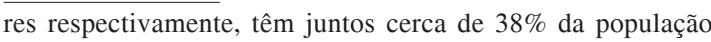
pentecostal nacional. O Rio de Janeiro é também o estado menos católico do Brasil, com apenas $55,71 \%$ da sua população adepta da confissão - este número é tributário não só das significativas cifras que atingem os evangélicos no estado, 21,98\% (aí incluindo-se os evangélicos de missão, 7,25\%, e os evangélicos pentecostais, $13,72 \%$ ), mas, principalmente, do crescimento dos sem-religião, que atingem a impressionante cifra de $15,76 \%$.

7. Segundo uma autodescrição, o intuito dessa organização é: "empenhar se em atender pastores e líderes da igreja brasileira. Nosso intuito é prover treinamentos, materiais práticos e de qualidade que ajudem os líderes a ministrarem fielmente, biblicamente e com êxito. Queremos ver o mundo alcançado com o evangelho. Cremos que a melhor maneira para atingirmos esse alvo é o desenvolvimento de igrejas saudáveis ao alcance das pessoas". In: http:// www.infobrasil.org/sepal.htm

8. Notamos que pesquisadores ligados à Pontifícia Universidade Católica do Rio de Janeiro (PUC-RJ) chegaram a conclusão similar após análise dos dados censitários (IBGE, 2000) (ver Jacob et. al., 2003). 
encontram-se justamente no interior do estado, mais precisamente nas regiões de ocupação mais antiga, como as do chamado "circuito histórico", em que não atingem a cifra dos 5\%, como na microrregião de Ouro Preto $(4,85 \%)$. Ao passo que nas regiões de ocupação mais recente, a mensagem pentecostal recebe significativa acolhida, chegando à casa dos $22,71 \%$, como na microrregião de Ipatinga.

É interessante notar que, embora os estudos sobre o pentecostalismo tenham crescido sobremaneira nos últimos anos, poucos são os que se dedicaram a compreender o fenômeno em Minas Gerais. Como observaremos a seguir, a grande maioria das pesquisas centrou seu foco no crescimento pentecostal e em seus motivadores, sendo praticamente ausente das preocupações um estudo sistematizado sobre os territórios brasileiros que se mostram refratários a sua presença, como o caso que apresentamos.

A literatura sobre o pentecostalismo no Brasil remonta à década de 1960 , quando cientistas sociais, de diversos matizes teóricos, viram como um "raio no céu aberto" da secularização o crescimento do que julgavam religiões mágicas. Assim, não tardaram a surgir as primeiras teorias explicativas do fenômeno que, não obstante as vicissitudes teóricas, analisaram o pentecostalismo como uma espécie de refúgio das massas (D’Epinay, 1970) desamparadas no processo de transição entre a sociedade tradicional e moderna. Dessa forma, os primeiros estudos, grosso modo, propunham uma equação que associava variáveis como migração, anomia e conversão.

Nesse sentido, o pentecostalismo era visto como tendo a função de adaptação do contingente populacional recém-migrado para a cidade, recriando espaços de sociabilidade aos quais estavam afeitos em seus lugares de origem (Willems, 1967). Ou como uma resposta à anomia, uma forma de preparação para a vida nas grandes cidades (Camargo, 1973), "uma das alternativas no processo de adaptação individual à sociedade moderna" (Souza, 1969, p. 18).

A despeito de ter se tornado uma teoria explicativa paradigmática para os estudos do pentecostalismo no Brasil, as teses de cunho funcionalista passam a ser duramente criticadas por estudos posteriores. ${ }^{9}$ Dessa forma, em finais dos anos de 1970, pesquisadores vão a campo no intuito de propor novas fórmulas para desvendar o crescimento pentecostal. Somam-se estudos que vão do veio marxista, como os de Rolim (1985), ou que reeditam as teses weberianas como os de Pierucci (1996 e 1997) e Prandi (1992). Nessa vertente explicativa, podemos elencar a tese recentemente defendida por Ricardo Mariano (2001) na USP, que tenta aliar as teses weberianas às teorias do marketing model (Stark e Iannaccone, 1993), no que Frigerio (2000) acredita ser "um novo paradigma em sociologia da religião" (2000, p. 125). Essas teses propõem, entre outras coisas, a primazia da oferta dos produtos religiosos sobre a demanda.

Um pouco distante desse debate, e sem pretensões de criar grandes paradigmas explicativos para o crescimento pentecostal - mas não perdendo de vista essa problemática -, outra gama de pesquisadores centra seus esforços em compreender os significados da conversão nas vidas concretas dos agentes sociais. Nesse sentido, surgem trabalhos que analisam o impacto da adesão pentecostal na esfera familiar (Machado, 1996), ou suas significações na recuperação do alcoolismo (Mariz, 1996). Ainda temos uma ampla variedade de estudos que tentam compreender a relação entre a adesão ao pentecostalismo e a atuação dos agentes sociais no espaço público. Destacamos o estudo empreendido pelo Iser (Fernandes, 1996), que analisa, entre outras questões, a participação dos evangélicos na política, bem como uma recente publicação que reuniu uma gama considerável de pesquisadores empenhados em analisar as relações entre a religião e o espaço público (Birman, 2003).

Pelo exposto, acreditamos ser oportuno propor um estudo que vise analisar as relações entre cultura local e adesão ao pentecostalismo. Por meio da comparação entre as microrregiões supracitadas, imaginamos que poderemos aprofundar algumas questões que já estão sugeridas nos dados do censo do IBGE 2000 (ver Jacob et al., 2003). Ao analisar variáveis como família, apego a tradição e baixa dinâmica demográfica

9. Para uma crítica às posturas funcionalistas, ver Fry e Howe (1975), Alves (1978), Page (1984), Monteiro (1999) e Mariano (2001), entre outros. 
como fatores que contribuem para o pequeno índice de adesão ao pentecostalismo, poderemos abrir um novo eixo de discussão, que relativizaria algumas vertentes analíticas, principalmente as que advogam a supremacia da oferta religiosa sobre a demanda de bens religiosos.

\section{Mineiridade e adesão religiosa}

Partimos da tese de que o pentecostalismo se beneficia e faz parte de um processo de hibridação cultural em que estruturas ou práticas discretas, ${ }^{10}$ que existiam de forma separada, combinam-se para gerar novas estruturas, objetos e práticas (Canclini, 2003). Em nosso entendimento, o processo de hibridação, embora não seja um fenômeno recente, aguça-se com o avanço da chamada ultramodernidade, que faz com que a sociedade organize-se cada vez mais como um conjunto de não-lugares (Augé, 2003), nos quais as fronteiras simbólicas vão ficando borradas, dando origem a verdadeiras zonas francas, onde não se pode classificar com segurança elementos pertencentes a essa ou àquela cultura (Pace, 1997). A fragilidade dessas fronteiras simbólicas potencializa para os indivíduos a possibilidade de trocas, em que cada um pode assumir alguma coisa do outro sem se preocupar com métodos de produção do bem simbólico de que se apropria (Sepúlveda, 1996).

Então, o pentecostalismo teria êxito em espaços sociais em que as identidades encontram-se descentradas (Hall, 2001), enquanto ficaria praticamente estagnado em regiões onde as identidades "ainda" se encontram unificadas (ou foram reorganizadas) a partir de dispositivos discursivos "centrados" e "coerentes". Nesse turno, não poderíamos ver a adesão ao pentecostalismo apenas como mais um processo de destradicionalização. Pois defendemos que $o$ pentecostalismo, embora cresça em contextos identitários plurais, "destradicionalizados", acaba utilizando a cultura local como substrato de seu discurso evangelístico, contribuindo não raras vezes para a manutenção, o reforço e até o ressurgimento de elementos culturais esquecidos ou apagados na memória coletiva.

10. É interessante ressaltar que, para Canclini (2003), estruturas discretas significam estruturas já hibridadas, ou seja, estruturas não puras.
Assim, tentamos perceber o modo como os indivíduos vinculam aspectos "tradicionais" de seu grupo e de sua "visão de mundo" com elementos introduzidos pela nova opção religiosa e pelo sistema de comportamento e crenças que são próprios a esta. Nesse sentido, acreditamos que a hibridação possa ocorrer por dois processos, por meio da "ressemantização", no qual um corpus simbólico emanado de um centro e adotado por uma localidade distante daquele pode manter-se formalmente, mas, ao mesmo tempo, ser "ressemantizado" de acordo com os conteúdos próprios da localidade que os adota; ou pela "ressimbolização", processo pelo qual conteúdos tradicionais e vinculados à experiência social de um grupo adquirem nova expressão por meio de formas simbólicas importadas.

Deste modo, acreditamos haver um complexo processo, no qual elementos tradicionais (locais) entrelaçam-se a elementos transversais (globais), adaptando as macronarrativas a contextos específicos. Como nos mostra Mafra (2000), a estrutura das igrejas pentecostais possibilita uma articulação entre o carisma de seus especialistas e os motivos dos agentes locais, aos quais se dirige a mensagem. É interessante ressaltar que não negligenciamos o fato de esse contato com o passado ser feito por intermédio de uma memória frágil, fragmentada, eventual e desinstitucionalizada (Hervieu-Léger, 1997); muito pelo contrário, essa seria uma das chaves de nossa argumentação. Ao nosso ver, a extrema mobilidade das crenças e convenções sociais nos dias que correm colocaria em xeque as grandes narrativas e com isso a autoridade das instituições universalizantes, o que levaria à substituição dessas por narrativas locais, muitas vezes rechaçadas pelo ímpeto homogeneizante moderno. É justamente a esse contexto que as estruturas pentecostais leves, maleáveis e sem o peso do tradicionalismo católico adaptam-se melhor.

Como já observamos, é notória a relação entre a identidade mineira, sua constituição histórica e a religião. Seja no senso comum, na arte, na mídia, ou em trabalhos acadêmicos, ${ }^{11} \mathrm{a}$

11. Ver Carrato (1968), Boschi (1985), Mello e Souza (1982 e 1999), entre outros. 
figura do mineiro vem sempre imbricada à da religião, católica é claro. Podemos dizer que essa realidade é tributária de uma conjuntura histórica em que as organizações leigas foram estimuladas pela parca presença institucional católica durante os séculos XVIII e XIX, após a proibição das ordens religiosas regulares. ${ }^{12}$

Destarte, o vácuo institucional vivido por Minas durante esse período contribuiu para a formação de um catolicismo leigo bastante contundente, com uma ativa participação na organização de ritos, festas, devoções aos santos protetores e, principalmente, uma estreita intimidade com essa variante de culto católico. Em nosso entendimento, como já observamos em trabalhos anteriores (ver Gracino Júnior, 2003a e 2003b), essa proximidade entre fiel e culto católico gera um sentimento identitário muito forte, em que os mitos de origem confundem-se com os mitos católicos adaptados e/ou ressignificados nas diversas localidades, tornando os agentes bastante refratários à mensagem pentecostal.

Da forma como está exposto, o nosso problema de pesquisa parece uma equação de simples solução. Isso se nos perguntássemos, somente, por que não crescem os pentecostais em Minas. Ou melhor, por que não crescem nas regiões de ocupação mais antiga, ao passo que crescem vertiginosamente nas regiões de ocupação mais recente? Nesse sentido, permitimo-nos agregar mais algumas variáveis ao problema.

$\mathrm{Na}$ verdade, o que propomos é que a formação de um contexto identitário bastante demarcado, como a mineiridade, perpassado aqui e ali pelo discurso católico, serve como entrave ao crescimento pentecostal, por três fatores fundamentais:

- primeiro porque o catolicismo está intimamente ligado à família mineira, dando

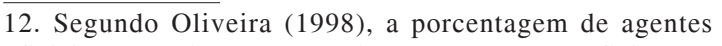
oficiais da Igreja era bem baixa em relação aos fiéis e ao território que abrangia a paróquia. Conforme o próprio autor, esse fenômeno era decorrente do regime do padroado, que unia Igreja e Estado. Nesse regime, a coroa portuguesa e posteriormente a imperial pagava as côngruas dos párocos colados. Isso a fazia desencorajar a formação de novas paróquias, sem falar na proibição das ordens religiosas na capitânia que vai até 1822, com a inauguração do Colégio do Caraça (primeira instituição religiosa ligada a uma ordem regular estabelecida em Minas Gerais).
}

substrato à mineiridade e criando um contexto cultural amplamente regulamentado, em que as trocas simbólicas tornam-se bastante difíceis;

- depois, por ter se tornado um patrimônio cultural do estado. É impossível pensar Minas Gerais hoje sem pensar nas grandes festas religiosas, como as festas do Rosário e a Semana Santa, que atraem milhares de turistas todos os anos às cidades mineiras. A religião e seus produtos (festas, imagens, ritos) foram incorporados aos circuitos comerciais, no que Canclini chama de "culturas populares prósperas" (2003, p. 216);

- por último, podemos ressaltar a tradição mineira, que ressurge como um porto seguro diante das tempestades da modernização, da desagregação das instituições e do anonimato nas sociedades contemporâneas.

Embora vários teóricos tenham trabalhado essa "musealização social" (Jeudy, 1990), ou com essa "sedução da memória" (Huyssen, 2000), é mais uma vez Nestor Garcia Canclini quem consegue captar com precisão esse processo em sua forma empírica:

O que é província para o senhor? - perguntaram ao folclorista Felix Coluccio no final de 1987; ele respondeu: “É a alma do País. Quando penso em uma salvação possível, vejo que só poderia vir de lá. No interior estão mais seguros as permanências dos valores culturais, o respeito a tradição e, sobretudo, porque as comunidades fazem algo transcendente por eles respeitando a tradição". (Carlos Ulanovsky, citado por Canclini, 2003, p. 161)

De forma similar, a mineiridade, que já foi vista como símbolo de atraso, do tradicionalismo interiorano, do caipira supersticioso apegado a santos, promessas e novenas, hoje é encarada como uma saída, um modelo para uma sociedade em crise.

Nesse ponto, parece-nos oportuno adensarmos um pouco mais o conceito de mineiridade, bem como sua relação com o problema que propomos.

Tomamos a mineiridade como um dispositivo discursivo, que visa dar unidade a um ema- 
ranhado cultural que é perpassado por diversas formas identitárias locais. O conceito de identidade, como nos lembra Stuart Hall, é um desses conceitos que operam "sob rasura", uma idéia que não pode ser pensada mais da forma antiga, mas sem a qual certas questões-chave não podem nem ser pensadas (2000).

Há "várias Minas e muitas Gerais", no entanto, a ficção da mineiridade, longe de ser ahistórica, é fruto de uma conjunção de fatores que podem ser mais bem compreendidos se colocados em seus contextos históricos específicos. Parece-nos óbvio, hoje, que o espectro identitário mineiro, como qualquer outro, não emane de um passado atemporal ou faça parte da personalidade herdada de uma miríade de povos (com destaque para os bandeirantes, que se instalaram em Minas no passado), nem tampouco que tenham tomado vida na pena de Alceu Amoroso Lima, em seu Voz de Minas (1946). É antes de tudo uma invenção, nos termos que coloca Hobsbawn (1984), refundada todos os dias, apropriada e reapropriada de forma diversa em cada momento pelos agentes envolvidos.

Acontece que esse arrazoado é imprescindível para a vida em sociedade, principalmente em uma sociedade que se desmorona a nossos olhos. Seria uma espécie de "fundo de conhecimentos à mão" (Schütz, 1967, p 13, citado por Bauman, 1998, p. 17), que nos daria segurança de agir acreditando na permutabilidade dos pontos de vista. Dessa forma, como argumenta Bauman (1998), "essas receitas" funcionariam como um dispositivo de segurança para a ação dos indivíduos em sociedade. Nesses termos, a mineiridade seria como que "um mapa" das Minas e das Gerais, que, embora não tenha sido fruto direto da pena dos ideólogos do estado, como Amoroso Lima, facilitou e facilita a tarefa classificatória daquele. ${ }^{13}$

Por outro lado, se para o estado é importante construir as Minas e planejar as Gerais (Barbosa, 1993), para a população inscrita em determinada faixa de seu território isso se torna uma oportunidade de navegar de forma mais segura

13. Podemos observar aqui as assertivas de Castells (2002), sobre o que o autor denomina "identidade legitimadora", mediada pelas instituições estatais no intuito de racionalizar e ampliar o controle sobre os atores sociais. em meio ao caldeirão identitário, de desenvolver suas relações sociais em um ambiente, aparentemente, de maior previsibilidade.

Acreditamos que esse "conforto" para com os discursos da mineiridade aumenta à medida que os elementos que compõe esse discurso identitário são personificados por eventos e heróis que estão "próximos" espacialmente e temporalmente das localidades que as utilizam. Em contrapartida, esse "conforto" tende a diminuir à medida que os elementos identitários afastam-se do espaço sócio-simbólico evocados para sua criação. Nossa hipótese é a de que a dimensão atemporal da memória que evoca os grandes mártires e acontecimentos de um passado glorioso mineiro, chamados agora a compor a mineiridade, não são partilhados de forma comum a todos das Minas e das Gerais. Antes, são dispositivos identitários típicos de uma região, tomados de parte como um todo.

Desta forma, a voz que Alceu Amoroso Lima queria ouvir não é a das Gerais, mas, sim, a das Minas, dos seus homens de grossa ventura, que ergueram monumentos, que se levantaram (moderadamente) contra a exploração colonial portuguesa, que geraram riquezas, materiais e culturais. O mineiro aclamado é o republicano, o conciliador, o libertário, o mártir, como Tiradentes ou Tancredo Neves, que, com o sacrifício da própria vida, defendem os seus ideais e a liberdade. O mineiro é gente simples, trabalhador honesto, que valoriza a família e, acima de tudo, é católico. Como demonstram esses excertos do editorial do Estado de Minas de 16 de julho de 1980:

Era 1696. E naquele dia crepitava em Mariana a chama de brasilidade que ardia no peito de intrépidos bandeirantes do desbravamento, transformando-se, em termos de trabalho, no primeiro acampamento - verdadeiro embrião da sociedade ativa e operosa [...]. O gênio bandeirante Salvador Fernandes Furtado, chefe da expedição, não demorou [...] na determinação de erigir, dia seguinte, o padrão de conquista em torno do qual o capelão Padre Francisco Gonçalves Lopez rezou a primeira missa. Estava fundado o arraial, predecessor dos Bispados, a que sucederam a primeira Vila, a primeira Cidade e, posteriormente, a primeira Capital de Minas, centro irradiador de ação civilizadora. [...] 
[O mineiro] Existe, e de maneira indiscutível, projetado na História. Do garimpeiro é a silenciosa pertinácia, a capacidade de trabalho duro, principalmente o apego a esperança que o sustenta, nos altos e baixos da vida que passa. As cidades nasceram sob tal signo. Também se reflete na História a religião de berço, expressa nas capelinhas, que logo sugiram, nas igrejas que se construíram, no centro do casario. $^{14}$

Para uma boa parte dos habitantes das Minas Gerais, esses arrazoados, além de remetêlos às suas memórias fundadoras, vivenciadas no seu dia-a-dia por meio dos infinitos lugares de memória (Nora, 1993), espalhados pelo espaço das cidades ou do campo, soam-lhes bem aos ouvidos. São espaços que lhes reafirmam a identidade e, conseqüentemente, o poder.

Temos ainda, em várias cidades do interior de Minas Gerais, a queda na produção industrial, com o fechamento de várias unidades produtivas e a diminuição da mão-de-obra, que empurrou uma leva considerável de trabalhadores para o setor terciário. No chamado "circuito histórico", por exemplo, o fechamento de postos de trabalho em virtude da diminuição da produção de minério de ferro, ou da "reestruturação produtiva", levou uma gama de trabalhadores, ex-operários das minas, a buscarem seu sustento no comércio, principalmente ligado ao turismo. Somados a esses fatos temos os ex-agricultores que viviam e vivem em pequenos distritos dessa região, trabalhadores que abandonaram a prática agrícola e passaram a se dedicar ao artesanato, contando com incentivos públicos e privados. ${ }^{15}$

Assistimos em Minas Gerais a um processo semelhante ao descrito por Canclini (2003) para vários países latino-americanos, nos quais, devido

14. Editorial do jornal Estado de Minas, de 16 de julho de 1980 , por comemoração do Dia de Minas. É interessante ressaltar que o "Dia de Minas" foi criado por iniciativa de alguns pretensos membros da intelligentsia mineira e logo acatado pela imprensa e pelo governo, sendo instituído por decreto em 1979. A data faz alusão à chegada da primeira bandeira em Mariana, em 16 de julho de 1696.

15. Tomamos como exemplo aqui as várias iniciativas ligadas ao governo de Minas Gerais para fomentar o turismo histórico-cultural no estado, bem como iniciativas pontuais, como um projeto ligado à Universidade Federal de Ouro Preto, que, ironicamente, visa resgatar nas barbas acadêmicas o "popular" perdido das obras de arte esculpidas em pedra-sabão à contribuição de fatores similares aos supracitados, uma gama considerável de mão-de-obra tem se deslocado para o artesanato. Dessa forma, vemos multiplicarem-se os produtos derivados do turismo histórico, sejam eles de ordem material como as imagens de santo (esculpidas em madeira ou em pedra-sabão), e a comida típica (que impulsiona o turismo gastronômico), ou imaterial, como as festas religiosas ou as datas cívicas comemorativas (como o 21 de abril), que atraem uma multidão de turistas às Minas Gerais.

Transitar identitariamente para fora da mineiridade, para inúmeros habitantes das Minas, é deixar escapar todo um filão comercial que se apresenta com uma gama de vorazes consumidores ávidos por se deliciarem com os tradicionais pratos da culinária mineira, ou se ver tête-à-tête com as inebriantes histórias contadas pelos imaginativos guias turísticos das cidades históricas.

A mineiridade torna-se produto, seja pela singeleza da vida cotidiana das cidades do interior ou pela constituição das comunidades, estas que não encontramos mais nas grandes cidades e das quais - para lembrar Bauman (2003) - estamos em busca. Essa identidade encenada, almejada, serve de palco e modelo para os peripatéticos discursos reacionários de todos os matizes. A família ideal, o modo de vida idílico do interior, a harmonia são exaltados como modelos a serem seguidos por aqueles que já não os têm ou nunca os possuíram. Essa teatralização é um esforço para simular que há uma origem, uma substância fundadora, em relação à qual deveríamos e devemos atuar hoje (Canclini, 2003).

Desta forma, acreditamos que recompor a identidade em outras bases, em regiões como a de Ouro Preto, significa distanciar-se de toda uma rede de significados e convívio social, que afetam não só culturalmente o modo de vida dos atores sociais, mas sua sobrevivência do ponto de vista econômico. Ser mineiro é pertencer a uma família, romper com a mineiridade é romper com essa família e perder o nome, perder o lastro, ficar à deriva em uma sociedade que mostra poucos sinais claros e direções seguras. 


\section{Considerações finais}

Embora não acreditemos em uma ruptura drástica entre o modus vivendi católico e o evangélico pentecostal, faz-se importante reafirmar nossa argumentação neste momento do texto. Acreditamos que a passagem ao pentecostalismo, ainda que promova um trabalho de realocação dos símbolos já partilhados pela cultura católica, o faz por anteposição a ela. $\mathrm{O}$ que argumentamos é que, ao contrário dos que abraçam a conversão como unidade de análise, não vemos processo de ruptura, principalmente no plano cultural.

Acreditamos, e trabalhos anteriores nos mostram isso (Gracino Júnior, 2003a e b), que não faça sentido, estratégico principalmente, para os agentes envolvidos romperem com sistemas identitários nos quais eles se sintam "confortáveis" e/ou que lhes promovam ganhos sociais e culturais. Então, nessa perspectiva, a passagem ao pentecostalismo dificilmente se daria em contextos identitários como os descritos aqui, a não ser por uma faixa bastante restrita da população, que vê na reorientação religiosa uma estratégia de inserção social ou cultural.

Notamos que não podemos acatar aqui, de forma alguma, o argumento da ausência de oferta do "produto religioso" (Mariano, 2001), pois a presença protestante na região remonta ao século XIX, com a vinda de um grupo significativo de ingleses para explorarem ouro na mina de Passagem de Mariana, ou com a primeira missão assembleiana no município, que data de 1957 (Gracino Júnior, 2003a). Podemos imaginar que, para usar um termo de Bourdieu (1987), o mercado de bens simbólicos dessa região é amplamente dominado pelo catolicismo. Considerando ainda o que nos diz o próprio Bourdieu (1987, p. 90) - que "o tipo de legitimidade religiosa que uma instância religiosa pode invocar depende da posição que ocupa num determinado estado das relações de força religiosa" -, pode-se imaginar que os insignificantes índices quanto ao pluralismo religioso mostram uma realidade sociocultural em que se torna difícil uma opção religiosa acatólica.
Abstract: In this study we concentrate in the variables that contribute to the asymmetric relation that we find in the religious affiliation process in the territory of Minas Gerais. As we can observe through the percentiles extracted from the tables of the recent Brazilian census (IBGE, 2000), the most of the Minas Gerais State seems to be hostile to the pentecostal growth. It looks like, as also occurs in another Brazilian States, a movement of catholic resistance against the penetration of the pentecostalism in that territory. However, in contrast with smaller areas, represented by cities as Ouro Preto, where the persons that declare themselves as pentecostals are represented by less than $5 \%$ of the population, there are other cities, as Ipatinga, for example, that presents an important population of pentecostals that comes to $22,71 \%$ of the whole, the higher of the State. Thus, we think that it's possible to relation the percents mentioned above to some characterists of the socio-cultural context of the State, with emphasis in the local identity, want we call "mineira". Summing up, we will evaluate as the influence of family, the low taxes of demographic mobility of the local population, as well as the notorious catholic tradition that marks the State population, in order to create a regulated cultural scenery, adverse to pentecostal growth.

Key-words: pentecostalism; local culture; mineiridade; identity.

\section{Referências}

ALVES, Rubem A. A volta do sagrado: os caminhos da sociologia da religião no Brasil. Religião $e$ Sociedade, 3, p. 109-141, out. 1978.

ANTONIAZZI, Alberto. et. al. Nem anjos nem demônios. 2 ed. Petrópolis: Vozes, 1996.

ARRUDA, Maria A. do Nascimento. Mitologia da mineiridade. O imaginário mineiro na vida política $\mathrm{e}$ cultural do Brasil. São Paulo: Brasiliense, 1989.

AUGÉ, Marc. Não lugares - por uma introdução à antropologia da supermodernidade. Campinas: Papirus, 2003.

BARBOSA, Maria Lígia de O. Reconstruindo as Minas e planejando as Gerais: os engenheiros e a constituição dos grupos sociais. Campinas, 1993. Tese (Doutorado) - Unicamp.

BARBOSA, Daniel H Diniz. Minas, os mineiros e a mineiridade: traços de identidade, mito ou cultura política? UFMG, 2004. (Mimeo).

BAUMAN, Z. O mal-estar da pós-modernidade. Rio de Janeiro: Jorge Zahar, 1998.

Comunidade - A busca por segurança no mundo atual. Rio de Janeiro: Paz e Terra, 2003.

BERGER, Peter \& HUNTINGTON (Org). Muitas globalizações: diversidade cultural no mundo contemporâneo. São Paulo: Record, 2004. 
BIRMAN, Patrícia. Cultos de possessão e pentecostalismo no Brasil: passagens. Religião e Sociedade, 17/1-2, 1997.

. (Org.) Religião e espaço público. São Paulo: Attar Editorial, 2003.

BOMENY, Helena M. B. Guardiães da razão. Modernistas mineiros. Rio de Janeiro: Ed. UFRJ/ Edições Tempo Brasileiro, 1994.

BOURDIEU, Pierre. A economia das trocas simbólicas. São Paulo: Perspectiva, 1987.

CAMARGO, Candido Procópio F. de. Religiões em São Paulo. In: MARCONDES, J. V. (Org.). São Paulo: Espírito, povo, instituição. São Paulo: Pioneira, 1968.

(Org.). Católicos, protestantes, espíritas. Petrópolis: Vozes, 1973.

CANCLINI, Nestor Garcia. Culturas híbridas poderes oblíquos: estratégias para se entrar e sair da modernidade. São Paulo: Edusp, 2003.

Consumidores e cidadãos: conflitos multiculturais da globalização. Rio de Janeiro: Ed UFRJ, 2001.

CARRATO, José Ferreira. Igreja, iluminismo e escolas mineiras coloniais. São Paulo: Nacional, 1968.

CASTELLS, Manuel. A sociedade em rede. 2 ed. Rio de Janeiro: Paz e Terra, 1999.

. O poder da identidade. 3 ed. Rio de Janeiro: Paze Terra, 2002.

DELLA CAVA, Ralph. Igreja e estado no Brasil do século XX: sete monografias recentes sobre o catolicismo brasileiro, 1916/1964. Estudos Cebrap, 12, p. 5-52, abr-jun. 1975.

D'EPINAY, Christian Lalive. O refúgio das massas. Rio de Janeiro: Paz e Terra, 1970.

DULCI, Otávio Soares. As elites mineiras e a conciliação: a mineiridade como ideologia. Ciências sociais hoje - Anuário de Antropologia, Política e Sociologia. São Paulo: Anpocs/Cortez, 1984, p. 7-32. DURKHEIM, Emílio. Las formas elementares de la vida religiosa. Buenos Aires: Editorial Schapire, 1968.

FERNANDES, Rubem César (Org). Novo nascimento: os evangélicos em casa, na igreja e na política. Rio de Janeiro: Mauad, 1996.

FRIGERIO, Alejandro. Teorias econômicas aplicadas ao estudo da religião: em direção a um novo paradigma? BIB. Rio de Janeiro, n. 50, p 145-163, 2000.

FRY, Peter Henry, HOWE, Gary Nigel. Duas respostas à aflição: umbanda e pentecostalismo. Debate $e$ Crítica, p. 75-94, jul. 1975.
GRACINO JÚNIOR. Barracões barrocos: memória, poder e adesão religiosa em Mariana-MG. Rio de Janeiro, 2003a. Dissertação (Mestrado) - Programa de Pós-Graduação em Memória Social da Universidade Federal do Estado do Rio de Janeiro.

Cultura local, memória e adesão religiosa. Morpheus - Revista Eletrônica em Ciências Humanas, n. 3, 2003b.

. Visões da cidade: memória, poder e preservação em Mariana, MG. Vivência, v. 28, UFRN- Natal (RN), 2005.

HALL, Stuart. Quem precisa da identidade? In: SILVA, Tomaz Tadeu. (Org.). Identidade e diferença. Perspectiva dos estudos culturais. Petrópolis: Vozes, 2000.

. A identidade cultural na pós-modernidade. 6. ed. Rio de Janeiro: PD \&A Editora, 2001

HANNERZ, Ulf. Fluxos, fronteiras e híbridos: palavras-chave para a antropologia transnacional. Mana, 3(1), Rio de Janeiro, p. 07-39, 1997.

HERVIEU-LÉGER, Danièle. La religion pour mémoire. Paris: Cerf, 1993.

. Representam os surtos emocionais contemporâneos o fim da secularização ou o fim da religião? Religião \& Sociedade, 18 (1), p. 32-45, 1997.

HOBSBAWN, Eric; RANGER, Terence. (Orgs). A invenção das tradições. Rio de Janeiro: Paz e Terra, 1984.

HUYSSEN, Andréas. Seduzidos pela memória. Rio de Janeiro: Aeroplano, 2000.

JACOB, César Romero. Atlas da filiação religiosa e indicadores sociais no Brasil. Rio de Janeiro: Ed. PUC-Rio; São Paulo: Loyola, 2003.

JEUDY, Henri-Pierre. Memórias do social. São Paulo: Forense, 1990.

LIMA, Alceu Amoroso. Voz de Minas. Ensaio de sociologia regional brasileira. 2. ed. Rio de Janeiro: Livraria Agir Editora, 1946.

MACHADO, Maria das Dores Campos. Carismáticos e pentecostais: adesão religiosa na esfera familiar. Campinas: Autores Associados; São Paulo: Anpocs, 1996.

MAFRA, Clara Cristina. Relatos compartilhados: experiência de conversão entre brasileiros e portugueses. Mana. Rio de Janeiro, 6(1), p. 57-86, 2000.

MARIANO, Ricardo. Análise sociológica do crescimento pentecostal no Brasil. São Paulo, 2001. Tese (Doutorado em Sociologia) - FFLCH/USP.

MARIZ, Cecília Loreto. Libertação e ética: Uma análise do discurso dos pentecostais que se 
recuperaram do alcoolismo. In: ANTONIAZZI, Alberto. et. al. Nem anjos nem demônios. 2. ed. Petrópolis: Vozes, 1996. p. 204-224.

. A dinâmica das classificações no pentecostalismo brasileiro. In: SOUZA, Beatriz Muniz. et. al. (Org.). Sociologia da religião no Brasil: revisitando metodologia, classificações e técnicas de pesquisa. São Paulo: PUC-SP/ Umesp, 1998. p. 85-92

MARTIN, David. Tongues of fire: the explosion of protestantism in Latin America. Oxford: Blackwell, 1990.

MELLO E SOUZA, Laura de. Os desclassificados do ouro - a pobreza mineira no século XVIII. Rio de Janeiro: Graal, 1982.

. O diabo e a Terra de Santa Cruz. São Paulo:

Cia. das Letras, 1999.

MONTEIRO, Paula. Religiões e dilemas da sociedade brasileira. In: MICELI. Sérgio. O que ler nas ciências sociais brasileiras (1970-1998). Antropologia 1. São Paulo: Sumaré/ Brasília: Anpocs, 1999. p. 327-63

NORA, Pirre. Entre memória e história: a problemática dos lugares. História e cultura. Projeto História, (10), p. 7-28, 1993.

OLIVEIRA, Ronald Polito. Visitas pastorais de dom frei José da Santíssima Trindade (1821/1825). (Estabelecimento de texto e estudo de Ronald Polito e José Arnaldo Coêlho de Aguiar Lima). Belo Horizonte: Fundação João Pinheiro e Iepha/MG, 1998.

PACE, Enzo. Religião e globalização. In: ORO, Ari Pedro; STEIL, Carlos A. (Orgs.). Globalização $e$ religião. Petrópolis: Vozes, 1997. p.25-42

PAGE, John. Brasil para Cristo: the cultural construction of pentecostal networks in Brazil. New York, 1984. Tese (Doutorado em Antropologia) - New York University.

PIERUCCI, Antônio Flávio. Interesses religiosos dos sociólogos da religião. In: ORO, Ari Pedro; STEIL,
Carlos A. (Orgs.). Globalização e religião. Petrópolis: Vozes, 1996a. p. 249-262.

Reencantamento e dessecularização: a respeito do auto-engano em sociologia da religião. Novos Estudos, v. 49, Cebrap, 1997.

PRANDI, Reginaldo. Perto da magia, longe da política. Novos Estudos Cebrap, n. 34, p. 81-91, 1992. ROLIM, Francisco Cartaxo. Pentecostais no Brasil: uma interpretação sócio-religiosa. Rio de Janeiro: Vozes, 1985.

SEPÚLVEDA, J. Reinterpreting Chilen pentecostalism. Social Campass, n. 3. p. 299-318, 1996.

SOUZA, Beatriz Muniz de. A experiência da salvação: pentecostais em São Paulo. São Paulo: Duas Cidades, 1969.

Pentecostalismo. In: As religiões da humanidade. v. 4. São Paulo: Ed. Abril, 1973.

STARK, Rodney.; IANNACCONE, Laurence. Rational choice propositions about religious movements. Religion and social order, v. 3A, p. 241-261, 1993.

STOLL, David. Is Latin America turning protestant? the politics of evangelical growth. Berkeley: University of California Press, 1990.

WEBER, Max. Ensaios de sociologia. 3. ed. Rio de Janeiro: Zahar Editores, 1974.

Economía y sociedad: Esbozo de sociología comprensiva. México: Fondo de Cultura Económica, 1992.

A ética protestante e o espírito do capitalismo. 15. ed. São Paulo: Pioneira, 2000.

WILLEMS, Emilio. Followers of the new faith culture change and rise of protestantism in Brasil and Chile. Nashville: Vanderbilt University Press, 1967. 
